\title{
Cultivating fertile learning grounds: Collegiality, tacit knowledge and innovation in creative co-working spaces
}

\author{
Yosha Wijngaarden $^{\mathrm{a}, *}$, Erik Hitters ${ }^{\mathrm{b}}$, Pawan V. Bhansing ${ }^{\mathrm{a}}$ \\ ${ }^{\text {a }}$ Erasmus University Rotterdam, Erasmus School of History, Culture and Communication (ESHCC), Department of Arts \& Culture Studies, P.O. Box 1738, NL-3000 DR \\ Rotterdam, the Netherlands \\ ${ }^{\mathrm{b}}$ Erasmus University Rotterdam, Erasmus School of History, Culture and Communication (ESHCC), Department of Media \& Communication, P.O. Box 1738, NL-3000 DR \\ Rotterdam, the Netherlands
}

\section{A R T I C L E I N F O}

\section{Keywords:}

Innovation

Creative clusters

Agglomeration

Tacit knowledge

Co-working spaces

Collegiality

\begin{abstract}
A B S T R A C T
Recently, the rapid global rise in co-working spaces and shared workspaces has sparked a re-emergence of the clustering debate. Similar to the presumed innovative potential of (creative) clusters, such spaces are assumed to possess the power contribute to their users' innovativeness. This paper explores whether and how co-working and co-location could stimulate interactions and collaborations that potentially foster innovation in the creative industries.

By building upon 46 interviews with Dutch co-located creative entrepreneurs and workplace managers, we argue that agglomeration economies are rarely of an economic (or radical innovative) nature. However, coworking members socially benefit from reduced transaction costs, buzz and the exchange of (tacit) knowledge. Especially, we contend that through physical proximity and play, networks of surrogate collegiality can emerge. Such networks are vital in bridging the transition from creative and arts education to the development of a professional, entrepreneurial skill set, providing a fertile ground for potential innovative prospects. Nevertheless, as outlined by some of the critical approaches to clustering theory, proximity alone has not been a sufficient condition for collaboration and innovation. On the contrary, the conjunction of the professional and private sphere can be challenging for creative workers. Interpersonal frictions, rivalry and mismatching cultures of work have been issues that could be addressed by workplace managers.
\end{abstract}

\section{Introduction}

The creative and cultural industries are often hurrahed for their innovative capacities and their contribution to the knowledge economy (Florida, 2002; Garnham, 2005). Yet, how such innovations come about and how knowledge diffuses is difficult to determine (Pratt and Jeffcutt, 2009; Wijngaarden et al., 2019b). Innovation in the creative industries is often considered not a "technological big bang", but rather a "field of innovation", which is impacted by technology, regulation, organisation and situatedness in space and time (Pratt and Gornostaeva, 2009). It also tends to be much more a by-product of creative production, as well as very contextual in its occurrence (Wijngaarden et al., 2019b). Such 'on the job' innovation - the 'everyday problem solving' resulting in small innovations and eventually affording new products and services is especially distinctive for creative work (Green et al., 2007; Scott, 1999). In order to understand such practices of innovation, looking at micro-interactions in the creative and cultural industries is crucial
(Pratt and Jeffcutt, 2009). By these interactions, Pratt and Jeffcutt (2009) refer to exchanges that cross the boundaries of the formal and informal, commercial and non-commercial, and interactions between different fields in arts and culture. This research aims to further the understanding of such micro-interactions and innovation by means of a qualitative study of eight shared creative workspaces in The Netherlands.

Ever since the late 1990s, a significant share of the innovation literature has taken a macro-perspective, forwarding the concept of clusters and their innovative milieus (Cooke and Lazzeretti, 2008; O'Connor, 2004; Porter, 1998; Pratt, 1997; Shefer and Frenkel, 1998). Building upon the work of Sassen (1994) and Castells (1996), especially urban regions were considered the powerhouses of such new economies (O'Connor, 2004). Clusters - agglomerations of interconnected companies or institutions in a particular field (Porter, 2000) - were thought to provide benefits in reducing transaction costs, reinforcing transactional modes of social solidarity and accelerating the circulation of

\footnotetext{
* Corresponding author.

E-mail addresses: wijngaarden@eshcc.eur.nl (Y. Wijngaarden), hitters@eshcc.eur.nl (E. Hitters), b.pawan@gmail.com (P.V. Bhansing).
} 
capital and information (Scott, 2000). Economic geographers - especially on the macro-level - approach such clusters, agglomerations or communities of practice as a key to understand the "complex role of proximities in knowledge production and innovation" (Richardson, 2016, p. 2256).

Recently, we have witnessed a renewed interest in clustering on the micro-level in the worldwide emergence of co-working spaces, rising to a projected 22400 worldwide by the end of 2019 (DESKMAG, 2019). Many of such workplaces have been specifically targeting creative labourers as their audience due to the often individual and project-based nature of creative work and subsequently the relative abundance of freelance creative workers. Nevertheless, co-working spaces are not limited to creative work only, and cater to a much larger group of selfemployed entrepreneurs, groups of (outsourced) employees and other more hybrid forms of work.

For researchers interested in the development and diffusion of innovative practices, such places allow a more structural assessment of how innovation on a micro-level may or may not occur. Not surprisingly, many of the concepts derived from the traditional (creative) clustering literature are applied to co-working spaces without much hesitation (Fiorentino, 2018). Contrary to this agglomeration discourse culminating nearly two decades ago, which usually covered entire regions or cities, the agglomeration in co-working spaces demonstrates the working of such forces on the individual level. As face-to-face knowledge exchange of labourers has always been considered a source of innovation (Porter, 2000), such interactions can be even more influential in situations where an individual often equals the firm (in e.g. freelance work, which is the most prevalent form of creative industries labour organisation in The Netherlands (Koops and Rutten, 2017)). Similarly, co-location strongly influences backward and forward linkages, access to pools of specialised knowledge and labour, and flows of relevant information stimulating knowledge spill-overs (Storper and Venables, 2004). Nevertheless, how and whether such concepts apply in micro-settings remains an unresolved question.

We propose that by studying such flows of information, face-to-face interactions and collaborations, we will gain a better understanding of agglomeration economies on a micro-level, as well as the foundations of innovation in the creative industries. Moreover, even though the body of research on co-working spaces is growing, whether (and how) such co-working indeed leads to knowledge sharing and potentially innovation is unclear. Indeed, current research suggests that co-working does not necessarily lead to collaborative practices, knowledge spillovers and innovation (Fuzi, 2015; Merkel, 2015; Spinuzzi, 2012). Therefore, based on in-depth interviews with users and managers of Dutch shared workspaces, we aim to answer the question whether and how co-location, on the micro-level, stimulates interactions, collaborations and potentially innovation in the creative industries. A more rigorous exploration of such exchanges and interactions will generate a better understanding of the practices of co-located work in the creative industries, as well as the possibilities to strengthen the innovative capabilities of this field.

\section{Co-location and micro-interactions in the creative industries}

\subsection{Locality and the importance of face-to-face contact}

The co-working hype has strong roots in the cluster discourse that emerged in the early 2000s. In this earlier discourse on agglomeration, especially the work of Porter (2000) has been influential. Porter (2000, p. 15) defined clusters as "geographic concentrations of interconnected companies, specialised suppliers, service providers, firms in related industries, and associated institutions (e.g. universities, standards agencies, trade associations) in a particular field that compete but also co-operate". $\mathrm{He}$ argues that clusters facilitate economic growth and innovation through face-to-face contact among labourers. Such physical contacts may stimulate the formation of new businesses and trustful relationships (see also Urry, 2002). Moreover, these interactions are thought to facilitate a dynamic atmosphere that spurs innovation, lures talent, attracts investments, generates growth through a self-reinforcing endogenous process (Turok, 2003), and helps creative workers develop languages, rites and other code keys for communication (Lorenzen and Frederiksen, 2008). Social proximity, this perspective posits, enhances interactive processes allowing knowledge exchange (tacit and codified), collective learning and innovation (Bassett et al., 2002; Malmberg et al., 2005).

These social aspects - mutual trust, face-to-face contacts and shared language as buildings blocks of innovation - indicate that modern developments such as the 'weightless economy' or 'the end of geography' (Pratt, 1997, 2000) and the increasing individualisation, atomisation and isolation of creative work (McRobbie, 2016) have not obviated the need for co-presence and social interactions (Storper and Venables, 2004; Urry, 2002). Especially in the creative industries, conceivably caused by the highly insecure nature of these industries, the local community and networks are paramount for professional and creative success (Gill and Pratt, 2008; Hesmondhalgh, 2012; Neff et al., 2005). Indeed, the creative industries are associated with an exceptional dependency on local cultures and networks, relying more than other industries on 'sticky' places (O'Connor, 2004). This obviously too has had a tremendous effect on the ways in which (creative) labour is structured. The backdrop of a growing freelance workforce requiring peer co-presence has catalysed the emergence of thousands of co-working spaces throughout the world.

However, this perspective has been criticised as well, with authors (e.g. Pratt, 2000) arguing that such an 'affective community' or a 'place to be' cannot not be seen as an instant panacea for innovation. In practice, co-location alone rarely seems to be sufficient in sustaining a fertile learning ground in which firms relatively easily emerge and flourish. As Saxenian (1994) argues: "The simple fact of spatial proximity evidently reveals little about the ability of firms to respond to the fastchanging markets and technologies that now characterize international competition." Indeed, she notes that "concepts of agglomeration and external economies cannot explain why clusters of specialized technical skill, suppliers, and information produced a self-reinforcing dynamic of increasing industrial advantage in Silicon Valley while producing stagnation and decline along Route 128" (p. 6). A growing body of research in (but not limited to) critical labour studies, feminist geographies, and political and cultural economics have aimed to incorporate other dimensions including the local institutions and (corporate) cultures (see e.g. Schoenberger, 1997), industrial structures, and corporate organisation. In line with what is called the 'cultural turn', the cultural dimensions such as (gender) roles (Richardson, 2018), (local) norms, beliefs, and expectations - have become more prominent in the discourse on place (Garnham, 2005; Ettlinger, 2003). In this, different kind of interactional ties and practices result in differences in effectiveness and local entrepreneurial success.

\subsection{Tacit knowledge and entrepreneurial learning processes}

Especially for workers in the creative industries, uncertain social and economic conditions for many - particularly freelance - workers force them to advance and exhibit their entrepreneurialism (Banks and Hesmondhalgh, 2009; Bridgstock and Cunningham, 2016; Butcher, 2018; Gill and Pratt, 2008; Hesmondhalgh and Baker, 2010). Yet, such entrepreneurial skills are not self-evident and often only taught superficially (if at all) in arts or creative industries education (Bridgstock, 2013; Oakley, 2014; Raffo et al., 2000). Much of this knowledge is therefore acquired tacitly. Such tacit knowledge refers the form of knowledge famously described by Polanyi (1967, p. 4) as "[w]e can know more than we can tell" [italics in original text]. It incorporates procedural knowledge transferred through practice, observation and sharing. Tacit knowledge is thought to be transferred only through faceto-face interactions (Lundvall, 1992) between partners who already 
share some basic similarities, such as languages, codes and personal knowledge (either formal or informal) (Nonaka, 1994).

Proximity, by means of the circulation of tacit knowledge, allows for the diffusion of best practices, which potentially increases the competitiveness and innovativeness of places and creative workers (Capdevila, 2013). Co-locating and subsequent informal interactions afford such learning and the development of entrepreneurial social capital (Alacovska, 2018; Butcher, 2018; Gandini, 2015; Spinuzzi, 2012). Not surprisingly, therefore, tacit knowledge takes a central argument in the clustering discourse, as serendipitously acquired, locally embedded, 'sticky' skills and know-how (cf. Comunian and England, 2019) are thought to provide competitive advantages in learning and innovation. This idea has especially resonated in the creative industries, which are, even more than other sectors, associated with learning-bydoing, intuitive work, and a lack of organisational and institutional support (O'Connor, 2004; Olma, 2016; Rae, 2004; Raffo et al., 2000).

Obviously, tacit knowledge is more easily acquired in a 'buzzing' environment. Through such social structures, actors may contribute to and benefit from the diffusion of information, gossip and news by just 'being there' (Bathelt et al., 2004, p. 20). It also allows imitation and increased competition (Storper and Venables, 2004), which are important incentives for innovation and differentiation (Porter, 1998). Especially in the creative industries, buzz is considered to be crucial for knowledge exchange because they are, more than most other industries, dependent upon tacit knowledge in terms of production, and on social networks in finding suitable project-members (Asheim et al., 2007). Yet, little is known about the specific nature and practices of such learning and knowledge exchange in the creative industries, e.g. how and which knowledge is exchanged (Cohendet et al., 2014; Pratt, 2014; Brown, 2017), how actors build trust to do so (Richardson, 2016), how entrepreneurial or creative skills are acquired (Butcher, 2018; Rae, 2004; Raffo et al., 2000), and under which conditions this occurs.

Especially because simply co-location alone may not always stimulate such interactions and collaborations - and curation is thought to be essential for stimulating collaborative and innovative efforts (Brown, 2017; Fuzi, 2015; Merkel, 2015; Parrino, 2015; Richardson, 2017) attention to local firm cultures (Schoenberger, 1997) and social interactions and emotions in micro-space settings (Ettlinger, 2003; Richardson, 2016) may provide further insights in such mechanisms.

\subsection{Communities (of practice) and collegiality}

Tacit knowledge is thought to be exchanged intensively in communities of practice (Amin and Roberts, 2008; Brown and Duguid, 1991; Wenger, 1999). Membership of such communities requires participation in local everyday practices (Handley et al., 2007). It goes beyond 'being there' (Gertler, 1995), but also concerns the learning the essential roles and performances (Goffman, 1959). Yet, much of the communities of practice literature focuses on small groups united by a common skill or task, including sustained mutual relationships, knowledge of the knowledge of others, local stories and inside jokes, a shared discourse, jargon and rapid flows of information (Amin and Roberts, 2008).

Co-working in its original form, nevertheless, revolves around community (Spinuzzi et al., 2019). For co-workers, the promises of community are more often a reason for co-working than the networking opportunities (Brown, 2017). Such communities can - but not necessarily have to - increase productivity or foster project collaboration (Garrett et al., 2017). Nevertheless, many practices have a non-economic and informal nature (Alacovska, 2018), with co-working spaces being a formal organisation intentionally providing access to such informality to its members (Blagoev et al., 2019). As briefly described above, especially in precarious conditions, workers tend to work 'relationally' and in collective solidarity, drawing upon informal, interpersonal and meaningful efforts (Vidaillet and Bousalham, 2018) and more altruistic and collegial motives (Alacovska, 2018). This ties in with the work of Ross (2003) on post-Fordist work practices in IT workplaces around the turn of the century, which he considered especially 'collegial'. Notwithstanding the benefits of communities, Ross (2003) argues that such workplaces are not necessarily just. Though at the one hand - seemingly - being oriented towards collective selfgratification, this 'new economy' bears little sympathy to those that fail to keep up. Community, in this sense, should be considered with caution. Though generally invoked as something positive, the glue of society binding people together, Joseph (2002) warns us that communities are not utopian, organic occurrences producing unity. On the contrary, they furnish and justify a wide range of practices of exclusion. Following this argument, communities in co-working spaces need to be explored not only through the lens of what an actor might gain in terms of e.g. innovation, but also which actors do not have access to these gains (and why).

Spinuzzi et al. (2019) describe such a co-working community drawing upon the work of Tönnies (1963) and Adler et al. (2007) as a 'third' organisational form besides gemeinschaft and gesellschaft. Such a collaborative community is oriented towards mutual understanding, trust, cross-disciplinary and collaborative work. However, notwithstanding the claims of the co-working discourse (Gandini, 2015; Parrino, 2015), Spinuzzi et al. (2019) argued, gesellschaft oriented logics - market-oriented, individualist and rational-legally justified - were more dominant than the collaborative logic. With communities often being considered to have a form of purpose beyond the social connection (Garrett et al., 2017), this evidently raises the question how communal co-working spaces actually are in practice (and to whom), or whether such workplaces are at best collegial. In this context, we see collegiality as a form of relational capital (Kale et al., 2000): the emotions of trust, mutual respect and friendship resulting from close and frequent inter-personal interaction among people in different networks (e.g. web designers and sculptors interacting on a regular basis, yet not necessarily collaborating).

\subsection{Co-presence and collaboration on the micro-level}

The physical configuration of co-working spaces and other forms of shared workspaces foster the development of 'co-present interaction', which is fundamental to social intercourse. Such co-presence provides access to rich conversations, including facial gestures, expressions, body language, intonation, silences, turn-taking practices and anticipation (Friedland and Boden, 1994). This social environment - the emergent urban entrepreneurial style (Fiorentino, 2018) and the proximity of peers for collaboration and exchange - are key in nurturing creativity and professional success. In this, collaboration is an inter-organisational way of managing a complex work environment.

Hence, looking into micro-interactions also enables us to provide empirical foundations for the more structural theoretical assumptions behind knowledge exchange and innovative practices in creative workplaces. Concepts from economic or cultural geography or economics - such as 'buzz' or agglomeration economies - are considered aggregates of micro-phenomena that are interpreted as macro-summaries (see e.g. Reveley and Down, 2009). Yet, though some work has encompassed the level of the people on the workfloor (e.g. Ettlinger, 2003; Schoenberger and Walker, 2017; McDowell, 2009), the notion that people or firms "cluster together to reduce the cost of searches and transactions, to share infrastructure and intermediate suppliers, and to facilitate matching of labor and employers" (Schoenberger and Walker, 2017 , p. 1) still prevails in the widespread idea of agglomeration economies. Obviously, such approaches may have had difficulties in accounting for such social ties on the micro-level (Boggs and Rantisi, 2003; Schoenberger and Walker, 2017), or the daily practices of informal work (Alacovska, 2018).

This also holds for the widely studied topics of individual creativity and innovativeness (e.g. Amabile, 1996; Hirst et al., 2009; Tierney et al., 1999). Here too, much less is known about the micro-level in 
relation to the clustering literature that historically focused on the regional (macro) and organisational (meso) level (Capdevila, 2013). In this paper, we aim to combine this micro-perspective with that of entrepreneurial learning and the emergent field of studies in co-working in order to gain a better empirical understanding of the dimensions and dynamics of interactions in such spaces.

In conclusion, we follow the argument of Capdevila (2013), who considers co-working spaces a form of micro-clusters, similar to the industrial cluster, yet, on a smaller level. In this, co-working spaces can be considered an alternative 'middleground' (Cohendet et al., 2010) that connects the 'upperground' - larger, formal organisations and institutions that focus on exploiting creative work - and the 'underground', the creative individuals (Capdevila, 2013, 2015). Capdevila (2013) indicates that such places enable the transfer of knowledge along members, mainly committing to relations with fellow co-workers and thereby refraining from the competitive mode of work. As such, this raises the question how the knowledge dynamics of cluster theory manifest in co-working spaces, and especially how an 'industrial atmosphere' (Marshall, 1919) can be studied in today's post-Fordist collaborative and flexible workspaces (Capdevila, 2013).

\section{Methods and data-collection}

\subsection{Research setting}

From the 1990s, many old, often industrial buildings were transformed into workplaces for creative firms in organic bottom-up initiatives or top-down developed projects. These creative clusters - offering flexible or co-working oriented workspaces - are growing in number and diversity, including for example co-working spaces, incubators, serviced offices and workspaces without any facilities (Fuzi, 2015; Weijs-Perrée et al., 2019). This research focuses on eight of such shared creative workspaces in The Netherlands: Belcanto in Haarlem, BINK36 in The Hague, Creative Factory in Rotterdam, De Gruyter Fabriek in Den Bosch, Klein Haarlem in Haarlem, De Vasim in Nijmegen, Dutch Game Garden in Utrecht and Strijp-S in Eindhoven.

\subsection{Data collection and analysis}

This research is built on participant observations in the eight locations, some 15 short pilot interviews, 46 in-depth interviews with colocated creative workers, and 8 interviews with the managers or directors of the co-working locations included in this project. Out of the 46 respondents, 17 identified as female, and 29 as male. Their ages covered the full scope of the labour force, with the youngest being recent graduates in their early 20s, and the oldest nearing retirement age. Nevertheless, they were by and large similar in ethnicity and educational background. The most important selection criterion for the creative workers was a self-reported relationship with creative work and having worked or working in one of the eight locations. The interviews took place from January 2014 to October 2015 and were held in the respondents' workplaces. The respondents worked in one or several of the DCMS sub-sectors of the creative industries: eight in advertising, one in architecture, six in arts and antiques, three in crafts, seven in design, two in designer fashion, six in digital and entertainment media, four in film, video, photography and seven in music, performing and visual arts and two in software and electronic publishing.

Given the duration of the fieldwork spanning over a year and the iterative course of data collection, coding and analysis (e.g. Strauss and Corbin, 1990), the topic lists have been subject to a continuous process of adjustment and readjustments, with the first pilot interviews being mostly open, respondent-led interviews and with a more specific and semi-structured approach in the in-depth interviews. Respondents were, among other topics, inquired about their daily practices in their workplaces, the networks in- and outside their locations, the activities they organised and participated in, their interactions with other creatives and their (prospected) collaborations. The locations' managers were asked about their experiences and choices in fostering interaction and cooperation among creative entrepreneurs, and interactions between managers and entrepreneurs. All interviews were recorded and transcribed to allow qualitative analysis. Finally, we conducted one month of participatory fieldwork in one particular location, as well as a total of approximately fifteen days in the other locations in order to immerse ourselves in the daily practices of creative work (Emerson et al., 2011).

In coding, we took a grounded theory (Strauss and Corbin, 1990) based approach in the sense that, despite our interest in the micro-aspects of cluster theory related concepts, we aimed to derive our analytic categories not from these preconceived concepts, but rather from the data (Charmaz, 2001). The goal therefore was not to test the clustering theory in micro-settings, but rather to understand patterns of interaction in collective workplaces and explore what co-working adds to clustering theory and vice versa.

The pilot interviews were analysed descriptively in order to determine relevant themes to follow up on as well as to develop a provisional topic list. For the first ten interviews, the data was coded using initial coding in order to continue on gathering an exhaustive list of codes and to capture as many ideas as possible (Friese, 2012; Saldaña, 2012). Again, these codes were clustered in what we considered summarising concepts, such as formal and informal collaboration, perceptions of collegiality and competition. In the later interviews as well as the field notes based on the ethnographic fieldwork, we proceeded with holistic coding in order to further develop the key themes for this research, focusing on the most salient patterns. Codes were then collected for closer scrutiny by rereading and recording whole corpus, and further explored through nested coding (Saldaña, 2012). By a combination of exploring recurring topics, similarities and differences, indigenous typologies (Ryan and Bernard, 2003), and the connection to the theories described above, four overarching themes were defined: [1] agglomeration externalities and formal collaboration, [2] tacit knowledge and entrepreneurial learning [3] communities and collegiality in freelance work, and [4] competition and the impact of cultural differences.

\section{Results}

\subsection{Agglomeration externalities and formal collaboration}

So, do (creative) workers reap the benefits of co-location, and if so, how? Or, in other words, do we see agglomeration externalities in micro-settings? To start with the most formalised form of interaction, collaboration, the results indicate that for most respondents, this was not a daily practice. This seems to confirm the many studies that demonstrate that non-transaction-based interaction in clusters occurs more often than for example buyer-supplier relations (Keeble et al., 1999; De Propris, 2002; Malmberg et al., 2005).

Nevertheless, if they did or sought to do, the reasons for formally collaborating within their local workplace can be categorised in three motives: convenience, trust and reciprocity. First, for many respondents, working on a project with people close by is a matter of convenience, resembling an alternative form of reduced transaction costs (Porter, 2000). For example, Jessica [Arts and Antiques] argued that it is very helpful to be "close to the source", because "you can get contacts anywhere, but it is incredibly nice to have [contacts] in your immediate area. It's like a bakery two towns away; eventually you'll stop going to that bakery".

For others, it was not only convenient, but also a matter of working with the people you know. Especially for project-based working, respondents use networks to find the right people for the right job. Meeting people frequently ensures that they stay in the 'awareness space' (Grabher, 2004), remaining close to their peers and competitors (see also Wijngaarden et al., 2019a). This proximity thus served not 
only as a means to collaborate, but also indirectly afforded more subtle benefits. Interacting and observing others allows the possibility to check potential partners' reliability and potentially builds trust. Banks et al. (2000) argue that trust is of high importance in project-based work in the creative industries. This is also visible in the respondents' narratives, stating, for example, that the closer they are to others, the easier it is to get recommendations, and the safer their choices for potential collaboration are. Evidently, remaining in this 'awareness space' also allowed them to stay informed about relevant changes and developments in their field.

Finally, formal collaboration often had a reciprocal nature. Some respondents enjoyed forwarding work to others that are in the same situation because they felt like they could identify with them as peers. In many locations, especially those that were more community oriented, we observed an informal market in projects and gigs (cf. Alacovska, 2018), with informal favour swapping and volunteering being a day-to-day practice. Regularly, the size of the project was a decisive factor in such exchanges: "the 'larger guys' passed a project, they said that it was too small for them, and perhaps it's something for us." [Louis, Design]. In some other cases, it was related to knowledge and specialisation. We also witnessed a few cases in which several co-located workers decided to present themselves under one flag to other firms and clients, in order to win projects that would have otherwise been out of their reach.

\subsection{Tacit knowledge exchange and entrepreneurial learning}

Nevertheless, formal collaboration usually remained very practical, with only rarely knowledge exchange sparking innovative practices. Similar to the findings of Ebbers (2013), inward and outward contracting (the exchange of paid business assignments), though occurring occasionally, was not frequent. Informal collaboration, conversely, was more prevalent and relevant. This often manifested in the form of the exchange of (usually tacit) knowledge. Especially substantive feedback and content-based informal collaboration were mentioned in the interviews. Many respondents explained that they often got 'stuck' in their creative work, and needed someone to vent their problems to, or to give them creative and/or entrepreneurial advice. Charlie [Film, Video and Photography] stated that "I find it very important not to work on my own. I like to interact with other people. Sometimes you can get stuck in circle thoughts, and then it is nice to be able to talk about it. And when someone reacts, and makes you see things from a different side, I like that." Later on, Charlie also explained how seeing things from this 'different side' helped her in developing her own professional niche and approach. Co-working, here, clearly served the goal of learning everyday entrepreneurial practices - learning-by-doing - and facilitated the ongoing development of a professional identity (Butcher, 2018).

Additionally, many respondents noted that they contacted other creatives in their vicinity in order to discuss the business aspects of creative work. In line with the findings of Hennekam and Bennett's (2016) quantitative study of creative entrepreneurs in The Netherlands, creative workers argued that such aspects were often lacking in their creative education. Justin [Digital and Entertainment Media] asks the larger companies for advice: "[These questions are] indeed mainly business stuff, like eh... we have this game... Do we have to make it free to play or do we need it, are we going to sell it for ten Euros or something? What do you think works best?" Here, co-working spaces served as an intermediary affording mentoring or master-apprentice relationships that would otherwise not emerge.

This indicates that the 'social reskilling' (Winkel et al., 2012) from more creative to entrepreneurial capabilities (Loots and Witteloostuijn, 2018) evidently is taking place in such collaborative workplaces, and that this allowed access to essential yet tacit knowledge (see also Comunian and England, 2019). With precariousness and self-exploitation being prevalent among young creative entrepreneurs (Banks and Hesmondhalgh, 2009; Bridgstock and Cunningham, 2016; Gill and
Pratt, 2008; Hennekam and Bennett, 2016; Hesmondhalgh and Baker, 2010), access to tacit knowledge helped in the transition period from graduation to entrepreneurial success. The co-working spaces therefore afforded not only their users' professional development and innovative practices, but also mitigated the limited training creative graduates have received in business skills (Bridgstock and Cunningham, 2016).

\subsection{Working alone, with 'colleagues'}

Thus, informal interactions are paramount for especially young creative workers. Co-working spaces have the capability to expose their members to a continuous buzz of information, gossip, norms and practices. This buzz is highly important for creative entrepreneurs and artists (cf. Asheim et al., 2007; Storper and Venables, 2004), because according to them, "you cannot do it just on your own" [Monique, Arts and Antiques; Louis, Design and Tom, Design]. Hearing other peoples' ideas, opinions and perspectives is a disruptive force that introduces new approaches and ideas to existing habits and methods. And, learning by seeing other people work, some respondents argued, helped them in their own professional development. Monique [Arts and Antiques] explains this exposure to new ideas in the following way: "You inspire each other. You go outside, smoke a cigarette, and sit next to someone you don't know who's also working in this building, and turns out to do something with really strange technological things and machines. And then you start thinking, and you think 'oh, this machine can do this, or that', and you start talking and you give each other advice, you get together, and that grows."

Next to smoking, an important catalyst for such community-driven exchanges can be found in playfulness (see also Clare, 2013; Cohendet and Simon, 2007). For example, one of the locations used to have a table tennis table. Its recent removal sparked complaints about the respondents' practices of social interaction being disturbed. They argued that, when they were stressed or 'stuck' in a creative process, they asked others to play table tennis with them, as Charlie [Film, Video \& Photography] illustrated. This makes the workspace a "professional playground" [James, Music, Visual and Performing Arts]. Similarly, drinks are also a prime event for picking up the buzz. In all locations, drinks were organised for tenants and other interested creatives. Most respondents indicated that, whenever time allowed, they participated in these drinks; not only for the (free) beer, but also in order to get to meet their neighbours and other creatives. Julia explained this by saying that, "as a freelancer, you're always on your own. You need the social aspects, which you can find during these drinks." Similar to the findings of Spinuzzi (2012), many enjoyed the social interactions, even if they did not lead to any formal or informal collaboration. Such places tended to solve the paradoxical situation for creative workers of 'lonerism' on the one hand, and the desire for peer recognition on the other (Lorenzen and Frederiksen, 2008).

Confirming Spinuzzi et al.'s statement that "coworking is about community" (2019), freelancers aimed to use co-working spaces in order to compensate for the challenges of self-employed creative work, most prominently the continuous intermingling of home, work and leisure, as well as the solitude that comes with such forms of labour organisation (Blagoev et al., 2019; Merkel, 2015). Yet, considering the high turnover rates in many of the workplaces, such communities were often diffuse, incomplete and temporary. Social contact in co-working spaces thus rather functions as a form of 'surrogate' collegiality in the sense that, despite not having an articulate common goal, many respondents appreciated the proximity of peers. Collegial in this context has more organisational social logics than 'third places' such as coffee bars, but is more bohemian and informal than traditional offices (Alacovska, 2018; Blagoev et al., 2019; Richardson, 2016).

Co-working spaces, nevertheless, compensated the lack of organisational and institutional support by being a social agglomeration effect. Despite not being formally colleagues in the sense that they lacked designated roles structuring and connecting their work (Richardson, 2016), many of the (freelance) respondents referred to their co-located 
creative peers in this collegial context, for instance as "colleagues from the departments of finance and marketing that know each other from day-today interactions and drinks, but do not deal with each other on a daily basis" [Sander, Digital and Entertainment Marketing]. For some respondents, this goes beyond superficial interactions: "We really laugh and cry together" [Kathryn, Designer Fashion]. These 'colleagues' offer a cure to the feeling of being "alone in the world", when "all your friends have normal jobs, you know, everyone has just a job", while as a creative entrepreneur, you live a different life [Mark, Software/Electronic Publishing]. Timothy [Advertising] even argues that there is nothing lonely about working alone in a co-working building, in fact, he considers it "less lonely than in a company in which a manager is continuously pressuring you to work harder".

A major incentive to collegial behaviour can be found in the practical obstacles of day-to-day work. Many of the interactions observed during fieldwork revolved around fixing broken office chairs, lending and borrowing laptop chargers or office equipment, watering plants and doing the dishes, or working around issues such as slow internet connections. Claire [Design] explained that she shared groceries with a group of co-working 'colleagues': "Basically we have a shopping list, and everyone contributes to the housekeeping, so one person does weekly shopping and then we put it here on the table for lunch". Often, such lunches and practical discussions led to forms of feedback and tacit-knowledge exchange, helping each other with WordPress issues or venting situations like the one Michelle [Digital and Entertainment Media] describes: "Just a talk at the coffee machine, sometimes you've got these questions, things that are not going well, someone not paying... how you deal with that? Just to vent your problems, like damn it, I don't know how to handle it".

These forms of "sense-making and reflective dialogue" (Comunian, 2017, p. 2) in which individuals develop a form of peer feedback and reflection, can only become fruitful in situations in which a shared sense of collegiality is developed (Brown, 2017). Collegiality is also thought to increase inspiration, especially in the smaller firms of the creative industries who are in a continuous balancing act between artistic and commercial imperatives (Jacobs, 2012; Loots and Witteloostuijn, 2018; Bhansing et al., 2018). These findings therefore indicate that collegiality is vital to the often-cited qualities such as buzz, collaboration and knowledge exchange. Yet, is the mere co-location (by means of ping pong or lunches) enough to spark such interactions?

\subsection{Competition and the impact of culture}

Even though it occurred regularly, knowledge exchange and local practices of innovation, especially in the form of formal collaboration, were not as prevalent as many of the managers and 'residents' hoped and expected to see. In fact, the lack of community and collaboration was considered a challenge that managers aimed to solve by organising events, designing 'collective' spaces for relaxation, or by clustering similar (in work or personality) tenants or members. Most prominently, this lack in collaboration and knowledge exchange was caused by respondents having an already existing network elsewhere, as well as very little time to invest in building a new, or enlarging their existing, network. Especially for older firms, collaboration was less frequent. Some were even critical of organised networking: "I wonder whether organising drinks stimulates [cooperation]. [...] [B]ecause yes, you need to invest your own time and such, and at this moment, that is just very costly" [Bjorn, Music, Visual and Performing Arts]. Though often considered an inseparable necessity for successful creative work, these activities, they felt, were only accessible to those that were less strained by the need to survive in a precarious position.

Others, however, had an entirely different reason for not engaging in such local collaborations: they refrained from having business relationships with people they would meet in their personal sphere because "at home, you don't sleep with your neighbour either" [Marcus, Advertising]. While appreciating having collegial contact with their neighbouring creative workers, they did not want to take the risk of spoiling this relationship with potential business conflicts. As Alex [Film, Video and Photography] argues: "Yes, the moment it becomes personal, I find it difficult to stay business-like. And eh, when you meet the next day and you're in a conflict about fees, I am just not like that, my character is not suited for that. I am a softy." The 'compulsory sociality' (Gregg and Seigworth, 2010) of such settings, for them, hampered their willingness to engage in the informal or formal market for collaborative work (Cockayne, 2016).

Some respondents experienced different issues, for example, by doing tasks for free, such as designing a flyer (as designer) or taking a picture (as photographer), mainly because they would feel uncomfortable asking money for this. For them, the local informal barter economy, in which spatial proximity was reflected in lower economic benefits, was hard to navigate (Alacovska, 2018). Similarly, Claire [Design] argued: "We try to keep [giving feedback] quite open, because you want honest feedback, but the more you become friends, the more difficult is to be very honest and direct". She also indicated that the diffusing boundaries between friends and co-workers have led to quite some tensions within her workspace. For many, primarily informal collaboration - or what we call collegiality - was more appropriate and often more fruitful than embarking on innovative projects together.

Despite being a rather homogeneous population, a healthy balance in cultures is important in cultivating the potential for knowledge exchange and innovations. Such a balance, according to the respondents, concerns both personal and professional characteristics. Sander [Digital and Entertainment Marketing], for example, explains how similarities in attitude are paramount for allowing successful social cohesion: "[Having the] same kind of people [creatives] is pleasant. Otherwise, people will collide. We don't want people here just wanting to show they have high hourly rates [...]. We want to walk around here on our flip flops or with skateboards if we want. The table tennis and a football table, you know, these things are important to us. We want to have that." On the other hand, Eric [Software/Electronic Publishing] explained that having too similar mind sets hampers innovation: "[What leads to innovation] is having multidisciplinary teams. When everyone is looking in different directions, you'll get new insights".

In line with the findings of Spinuzzi (2012), rivalry was not uncommon in the competitive creative industries. Nonetheless, many respondents emphasised that direct competition was limited, because, as Julia [Music, Visual and Performing Arts] explained, "Everyone just does their own thing. Just because they are eh, creatives. [...], [it] comes from the inside, the drive to do these things. So, it would be very coincidental if someone else does exactly the same thing. [...] I don't think that is the case here". Indeed, even within sub-disciplines of the creative industries, firms are very much specialised, which prevents too much overlap with other creatives nearby. Having the right proportion of (sectoral) diversity is therefore essential in maintaining an open, yet complementary atmosphere. "Everyone is in his or her own circle. It doesn't interfere with the work of others. Sometimes your roads cross, and you notice that you're both in the same pitch, but in general, no, we're not stealing each other's jobs, no, not like that", clarified Lucas [Music, Visual and Performing Arts]. Yet, for some, it was a thin line between healthy tension and serious competition. Especially among the larger firms also housed in shared workspaces, some respondents observed, doors were shut. This sometimes disappointed the other workers formerly working next to them: "When your firm grows, you become more closed. I don't like that. I hope I won't be like that in the future" [Rachel, Design].

\section{Conclusion and discussion}

\subsection{Conclusion}

Innovation in the creative industries has the tendency to occur 'on the job' and through 'everyday problem solving' (Green et al., 2007; Scott, 1999). This research aimed to investigate whether and how 
interactions between co-located creative workers promoted knowledge spillovers, collaboration and innovation in the creative industries. It also had the ambition to explore how concepts such as buzz, reduced transaction costs and knowledge spillovers manifest themselves on the micro-level.

This research adds to the clustering theory by highlighting that for co-working, agglomeration economies are rarely of an economic nature. On the contrary, though many co-workers paid a (substantial) fee, they rarely reaped direct benefits such as economic gains through formal collaboration (e.g. being 'hired' by another co-worker). Nevertheless, it did provide indispensable social externalities. Especially in the creative industries, where project ecologies are ubiquitous (Grabher, 2001), knowing who to work, collaborate and hang out with - in terms of specialisations, trustworthiness and matching personalities - is critical. Co-working spaces can be an essential tool for building and maintaining such a professional and personal network. We observed that for numerous co-located creative workers, these social promises are important, for example as a pool of informal exchange of help, advice or goods (cf. the work on creative slack of Cohendet and Simon, 2007). Convenience and physical closeness reduced transaction costs by saving time, effort and being able to have quick informal face-to-face deliberations. Proximity too stimulated the formation of new businesses and trustful relationships, as creatives remained in their peers' 'awareness space' (Grabher, 2004)

Moreover, respondents in this study also emphasised the buzz or 'industrial atmosphere' (Marshall, 1919) they experienced in especially 'third places' (Oldenburg, 1989; Brown, 2017): the coffee machines, smoking areas outside of the buildings, during lunch and around pingpong tables and other leisure facilities. These places were considered vital for discussing the state-of-the-art issues and ideas with peers, for staying informed about the latest gossip, and for learning the practices of creative entrepreneurship (cf. the idea of tacit knowledge as discussed by Gertler, 2003; Polanyi, 1967). They also afforded the development and persistence of local 'barter economies', in which informal help and work is exchanged (Alacovska, 2018). Using the terminology of Granovetter (1983), the results indicate that co-locating does not only grant them access to a web of strong ties, but also to a wider network of weak ties through informal interactions. Such interactions had the potential to expose the creative workers to innovative new ideas.

Co-working spaces - both by co-working hosts as well as by scholars - have been conceived and are still perceived as workplaces in which community logics are dominant. Spinuzzi et al. (2019) observed persistent market and economic rational dominance in many of such workplaces. This research partly confirms their findings, as communal values and collaboration are existing, yet not prevailing. However, we propose that such social practices could be categorised as 'surrogate' collegiality. Though not formally colleagues, co-located creatives have access to local social connections for informal help and social interactions. In a labour market where flexible, precarious freelance work dominates (Gill and Pratt, 2008; Hesmondhalgh, 2012; Hesmondhalgh and Baker, 2010; McRobbie, 2016), on the job training is limited, and in which creative and cultural industries education has not always embraced entrepreneurial skills and values (Bridgstock, 2013; Bridgstock and Cunningham, 2016), the co-working spaces function as a 'middleground'. Not only between formal organisations and creative individuals (Capdevila, 2013, 2015; Cohendet et al., 2010), but also between formal education and creative labour. Especially such a 'middleground' affords entrepreneurial and creative learning (Butcher, 2018).

Yet, the diffusion of such new ideas and skills is not self-evident. A significant number of respondents struggled with the 'compulsory sociality' and the distinct norms imposed by working in community settings (see also Joseph, 2002). Similar to Brown (2017), we observed that similarity in culture and values, as well as proficiency in the role of the 'creative worker', are important prerequisites for gaining access to knowledge flows and formal or informal collaboration. In other words, the cognitive distance between individuals (Nooteboom, 2000) should be limited. It also requires what are often called 'Jacobs externalities' (Galliano et al., 2015): interactions between diverse yet complimentary (sub)sectors. Such complementarity is also key in averting rivalry and competition. Even though Porter (1998) argued that this could be an incentive for innovation and differentiation, we observed that once firms grew beyond their original creative niche, the opportunities for knowledge exchange diminished.

In conclusion, our research corroborates the findings of Fuzi (2015), Merkel (2015) and Spinuzzi (2012) in the claim that co-working as a decisive factor in fostering collaboration and innovation is naive. Our results indicate that formal collaboration is limited, as is its contribution to radical innovative breakthroughs (e.g. the 'big bang' discussed by Pratt and Gornostaeva, 2009). Yet, looking at the micro-level, we learned that proximity is an essential facilitator of potential collaborative prospects. Offering help in practical issues is not considered explicitly innovative, but it contributes to a fertile ground aiding optimal personal creative and professional development. Such collegiality is unique for freelance creative workers, and provides a pool of ample (tacit) knowledge that has a potential to indirectly promote innovative new products, methods of production, markets or forms of organisation (Schumpeter, 1934).

\subsection{Discussion}

This research has focused on a diverse selection of creative flexible workspaces in the Netherlands. Even though it occasionally touched upon some of the differences between the eight locations, further research could include a more rigorous comparison of certain types of workspaces (Fuzi, 2015; Weijs-Perrée et al., 2019) in order to investigate their success in fostering innovation. Why did California's Silicon Valley thrive, and Massachusetts' Route 128 less so? Can we find similar patterns on the micro-level for co-working spaces? This would involve the distinction between more homogenous and heterogeneous groups of creative workers, more open and closed settings, the configuration of knowledge bases, the presence or absence of incubation programmes and the focus on the creative industries (as creative workers are distinct in motivation and growth opportunities, see e.g. Loots and Witteloostuijn, 2018). Such an approach would also allow deeper insights into the patterns of knowledge exchange in these collective workplaces.

It too is important to acknowledge that co-workers are not the only 'users' of such spaces. Their presence is facilitated by a wider range of (self-employed) staff members, including janitors, cleaners and technical staff. Moreover, workplaces too are not unidimensional entities in which behaviour and decision-making is guided by economic rationales only. Users - whether they are creatively skilled or less so, freelance or hired - - engage in social relations through social interactions (Ettlinger, 2003). Such interactions are charged by differences in power, friendship, competition or forms of collegiality. This also applies to the "nonmembers' of such spaces, such as this support staff, whose inclusion is not self-evident. Though in some locations they were integrated into the social fabric of the location, e.g. by collecting money for a leaving cleaning staff member, most respondents emphasised they had little in common with them. Similarly, the sample in this study is relatively homogeneous. Future research could explore how feelings of collegiality do or do not extend to other forms of necessary work, and whether these findings will also apply to more diverse groups of co-workers.

As such, co-working spaces can and need to be explored in the broader socio-economic-spatial context of wider changes in the realestate sector and labour market. What are the structural dynamics behind the emergence and persistence of such spaces? Are such workplaces only the result of agglomeration economies, or are there other forces at stake? Moreover, although existing research (e.g. Merkel, 2015) indicates little difference between countries, cross-national 
comparative research could confirm whether the results of this study would indeed also be applicable to other countries.

\section{CRediT authorship contribution statement}

Yosha Wijngaarden: Conceptualization, Methodology, Investigation, Writing - original draft, Writing - review \& editing. Erik Hitters: Conceptualization, Supervision, Project administration, Funding acquisition. Pawan V. Bhansing: Conceptualization.

\section{Declaration of Competing Interest}

The authors declare that they have no known competing financial interests or personal relationships that could have appeared to influence the work reported in this paper.

\section{Acknowledgements and Funding}

This work was supported by The Netherlands Organisation for Scientific Research (NWO) under the NWO Creative Industry grant [file number 314-99-110], and was made possible with the cooperation of the Dutch Creative Residency Network (DCR Network). The authors would like to thank two anonymous reviewers, Anouk Mols and Rian Koreman for their helpful comments on earlier versions of this paper.

\section{References}

Adler, P.S., Kwon, S.-W., Heckscher, C., 2007. Perspective-professional work: the emergence of collaborative community. Organ. Sci. 19 (2), 359-376. https://doi.org/ 10.1287 /orsc. 1070.0293.

Alacovska, A., 2018. Informal creative labour practices: a relational work perspective. Human Relat. 71 (12), 1563-1589. https://doi.org/10.1177/0018726718754991.

Amabile, T.M., 1996. Creativity in Context: Update to the Social Psychology of Creativity Routledge, Boulder.

Amin, A., Roberts, J., 2008. Knowing in action: beyond communities of practice. Res. Policy 37 (2), 353-369. https://doi.org/10.1016/j.respol.2007.11.003.

Asheim, B.T., Coenen, L., Vang, J., 2007. Face-to-face, buzz, and knowledge bases: sociospatial implications for learning, innovation, and innovation policy. Environ. Plann. C: Government Policy 25 (5), 655-670. https://doi.org/10.1068/c0648.

Banks, M., Hesmondhalgh, D., 2009. Looking for work in creative industries policy. Int. J. Cult. Policy 15 (4), 415-430. https://doi.org/10.1080/10286630902923323.

Banks, M., Lovatt, A., O'Connor, J., Raffo, C., 2000. Risk and trust in the cultural industries. Geoforum 31 (4), 453-464. https://doi.org/10.1016/S0016-7185(00) 00008-7.

Bassett, K., Griffiths, R., Smith, I., 2002. Cultural industries, cultural clusters and the city: the example of natural history film-making in Bristol. Geoforum 33 (2), 165-177. https://doi.org/10.1016/S0016-7185(01)00032-X.

Bathelt, H., Malmberg, A., Maskell, P., 2004. Clusters and knowledge: local buzz, global pipelines and the process of knowledge creation. Prog. Hum. Geogr. 28 (1), 31-56. https://doi.org/10.1191/0309132504ph469oa.

Bhansing, P.V., Hitters, E., Wijngaarden, Y., 2018. Passion inspires: motivations of creative entrepreneurs in creative business centres in the Netherlands. J. Entrepreneurship 27 (1), 1-24. https://doi.org/10.1177/0971355717738589.

Blagoev, B., Costas, J., Kärreman, D., 2019. 'We are all herd animals': community and organizationality in coworking spaces. Organization 1-23. https://doi.org/10.1177/ 1350508418821008.

Boggs, J.S., Rantisi, N.M., 2003. The "relational turn" in economic geography. J. Econ. Geogr. 3 (2), 109-116.

Bridgstock, R., 2013. Not a dirty word: arts entrepreneurship and higher education. Arts Humanities Higher Ed. 12 (2-3), 122-137. https://doi.org/10.1177/ 1474022212465725.

Bridgstock, R., Cunningham, S., 2016. Creative labour and graduate outcomes: implications for higher education and cultural policy. Int. J. Cult. Pol. 22 (1), 10-26. https:// doi.org/10.1080/10286632.2015.1101086.

Brown, J., 2017. Curating the "Third Place"? Coworking and the mediation of creativity. Geoforum 82, 112-126. https://doi.org/10.1016/j.geoforum.2017.04.006.

Brown, J.S., Duguid, P., 1991. Organizational learning and communities-of-practice: toward a unified view of working, learning, and innovation. Organ. Sci. 2 (1), 40-57.

Butcher, T., 2018. Learning everyday entrepreneurial practices through coworking. Manage. Learn. 49 (3), 327-345. https://doi.org/10.1177/1350507618757088.

Capdevila, I., 2013. Knowledge dynamics in localized communities: coworking spaces as microclusters (SSRN Scholarly Paper No. ID 2414121)

Capdevila, I., 2015. Co-working spaces and the localised dynamics of innovation in Barcelona. Int. J. Innovat. Manage. 19 (3), 1-25. https://doi.org/10.1142/ S1363919615400046.

Castells, M., 1996. The Rise of the Network Society. Blackwell Publishers, Cambridge, MA [etc.].
Charmaz, K., 2001. Grounded theory. In: Emerson, R.M. (Ed.), Contemporary Field Research: Perspectives and Formulations. Waveland Press, Prospect Heights, IL, pp. 335-352.

Clare, K., 2013. The essential role of place within the creative industries: boundaries, networks and play. Cities 34, 52.

Cockayne, D.G., 2016. Entrepreneurial affect: attachment to work practice in San Francisco's digital media sector. Environ. Plann. D: Soc. Space 34 (3), 456-473. https://doi.org/10.1177/0263775815618399.

Cohendet, P., Grandadam, D., Simon, L., 2010. The anatomy of the creative city. Ind. Innovat. 17 (1), 91-111. https://doi.org/10.1080/13662710903573869.

Cohendet, P., Grandadam, D., Simon, L., Capdevila, I., 2014. Epistemic communities, localization and the dynamics of knowledge creation. J. Econ. Geogr. 14 (5), 929-954. https://doi.org/10.1093/jeg/lbu018.

Cohendet, P., Simon, L., 2007. Playing across the playground: paradoxes of knowledge creation in the videogame firm. J. Org. Behavior 28 (5), 587-605. https://doi.org/10 1002/job.460.

Comunian, R., 2017. Temporary clusters and communities of practice in the creative economy festivals as temporary knowledge networks. Space Culture 20 (3), 329-343.

Comunian, R., England, L., 2019. Creative clusters and the evolution of knowledge and skills: from industrial to creative glassmaking. Geoforum 99, 238-247. https://doi. org/10.1016/j.geoforum.2018.02.009.

Cooke, P., Lazzeretti, L. (Eds.), 2008. Creative Cities, Cultural Clusters and Local Economic Development. Edward Elgar Publishing, Cheltenham.

De Propris, L., 2002. Types of innovation and inter-firm co-operation. Entrepreneurship Regional Dev. 14 (4), 337-353. https://doi.org/10.1080/08985620210144974.

DESKMAG, 2019. 2019 coworking forecast. Retrieved from < http://www.deskmag. com/en/1-7-million-members-will-work-in-coworking-spaces-by-the-end-of-2018survey $>$.

Ebbers, J.J., 2013. Networking behavior and contracting relationships among entrepreneurs in business incubators. Entrepreneurship Theory Pract. 38 (5), 1159-1181. https://doi.org/10.1111/etap.12032.

Emerson, R.M., Fretz, R.I., Shaw, L.L., 2011. Writing Ethnographic Fieldnotes. University of Chicago Press, Chicago.

Ettlinger, N., 2003. Cultural economic geography and a relational and microspace approach to trusts, rationalities, networks, and change in collaborative workplaces. J. Econ. Geogr. 3 (2), 145-171. https://doi.org/10.1093/jeg/3.2.145.

Fiorentino, S., 2018. Re-making urban economic geography. Start-ups, entrepreneurial support and the Makers Movement: a critical assessment of policy mobility in Rome. Geoforum 93, 116-119. https://doi.org/10.1016/j.geoforum.2018.05.016.

Florida, R.L., 2002. The Rise of the Creative Class: And How It's Transforming Work, Leisure, Community and Everyday Life. Basic Books, New York, NY.

Friedland, R., Boden, D. (Eds.), 1994. NowHere: Space, Time, and Modernity. University of Chicago Press, Chicago.

Friese, S., 2012. Qualitative Data Analysis With ATLAS.ti. SAGE Publications Ltd. London.

Fuzi, A., 2015. Co-working spaces for promoting entrepreneurship in sparse regions: the case of South Wales. Regional Stud., Regional Sci. 2 (1), 462-469. https://doi.org/10. 1080/21681376.2015.1072053.

Galliano, D., Magrini, M.-B., Triboulet, P., 2015. Marshall's versus Jacobs' externalities in firm innovation performance: the case of French industry. Regional Stud. 49 (11), 1840-1858. https://doi.org/10.1080/00343404.2014.950561.

Gandini, A., 2015. The rise of coworking spaces: a literature review. Ephemera 15, 193-205.

Garnham, N., 2005. From cultural to creative industries: an analysis of the implications of the "creative industries" approach to arts and media policy making in the United Kingdom. Int. J. Cult. Policy 11 (1), 15-29. https://doi.org/10.1080/ 10286630500067606.

Garrett, L.E., Spreitzer, G.M., Bacevice, P.A., 2017. Co-constructing a sense of community at work: the emergence of community in coworking spaces. Org. Stud. 38 (6) 821-842. https://doi.org/10.1177/0170840616685354.

Gertler, M.S., 1995. "Being there": proximity, organization, and culture in the development and adoption of advanced manufacturing technologies. Econ. Geogr. 71 (1), 1-26. https://doi.org/10.2307/144433.

Gertler, M.S., 2003. Tacit knowledge and the economic geography of context, or the undefinable tacitness of being (there). J. Econ. Geogr. 3 (1), 75-99. https://doi.org/ 10.1093/jeg/3.1.75.

Gill, R., Pratt, A.C., 2008. In the social factory? Immaterial labour, precariousness and cultural work. Theory, Cult. Soc. 25 (7-8), 1.

Goffman, E., 1959. The Presentation of Self in Everyday Life. Anchor, New York.

Grabher, G., 2001. Ecologies of creativity: the village, the group, and the heterarchic organisation of the British advertising industry. Environ. Plann. A 33 (2), 351-374.

Grabher, G., 2004. Learning in projects, remembering in networks? Communality, sociality, and connectivity in project ecologies. Eur. Urban Reg. Stud. 11 (2), 103-123. https://doi.org/10.1177/0969776404041417.

Granovetter, M.S., 1983. The strength of weak ties: a network theory revisited. Sociol. Theory 1, 201-233.

Green, L., Miles, I., Rutter, J., 2007. Hidden Innovation in the Creative Industries. [Working Paper]. NESTA, London.

Gregg, M., Seigworth, G.J., 2010. The Affect Theory Reader. Duke University Press, Durham and London.

Handley, K., Clark, T., Fincham, R., Sturdy, A., 2007. Researching situated learning participation, identity and practices in client-consultant relationships. Manage. Learn. 38 (2), 173-191. https://doi.org/10.1177/1350507607075774.

Hennekam, S., Bennett, D., 2016. Self-management of work in the creative industries in the Netherlands. Int. J. Arts Manage. 19 (1), 31-41.

Hesmondhalgh, D., 2012. The Cultural Industries. SAGE, London [etc.]. 
Hesmondhalgh, D., Baker, S., 2010. 'A very complicated version of freedom': conditions and experiences of creative labour in three cultural industries. Poetics 38 (1), 4-20. https://doi.org/10.1016/j.poetic.2009.10.001.

Hirst, G., Van Knippenberg, D., Zhou, J., 2009. A cross-level perspective on employee creativity: goal orientation, team learning behavior, and individual creativity. Acad. Manag. J. 52 (2), 280-293. https://doi.org/10.5465/amj.2009.37308035.

Jacobs, D., 2012. Creatief ondernemerschap en het dubbel succescriterium. Holland Manage. Rev. 2012 (146), 37-42.

Joseph, M., 2002. Against the Romance of Community. University of Minnesota Press, Minneapolis and London.

Kale, P., Singh, H., Perlmutter, H., 2000. Learning and protection of proprietary assets in strategic alliances: building relational capital. Strateg. Manag. J. 21 (3), 217-237.

Keeble, D., Lawson, C., Moore, B., Wilkinson, F., 1999. Collective learning processes, networking and 'institutional thickness" in the Cambridge region'. Regional Stud. 33 (4), 319-332. https://doi.org/10.1080/713693557.

Koops, O., Rutten, P., 2017. Monitor creatieve industrie 2016. Retrieved from < https:// www.neo-observatory.nl/monitor-creatieve-industrie-2016/ >

Loots, E., van Witteloostuijn, A., 2018. The growth puzzle in the creative industries. Revue de l'Entrepreneuriat 17 (1), 39-58.

Lorenzen, M., Frederiksen, L., 2008. Why do cultural industries cluster? Localization, urbanization, products and projects. In: Cooke, P., Lazzeretti, L. (Eds.), Creative Cities, Cultural Clusters and Local Development. Edward Elgar, Cheltenham.

Lundvall, B.-A., 1992. National Systems of Innovation: Towards a Theory of Innovation and Interactive Learning. Pinter, London.

Malmberg, A., Power, D., 2005. (How) Do (firms in) clusters create knowledge? Ind. Innovat. 12 (4), 409-431. https://doi.org/10.1080/13662710500381583.

Marshall, A., 1919. Industry and Trade: A Study of Industrial Technique and Business Organization, and of their Influences on the Conditions of Various Classes and Nations. MacMillan, London.

McDowell, L., 2009. Working Bodies: Interactive Service Employment and Workplace Identities. Wiley-Blackwell, Oxford.

McRobbie, A., 2016. Be Creative: Making a Living in the New Culture Industries. Polity Press, Cambridge, UK \& Malden, MA.

Merkel, J., 2015. Coworking in the city. Ephemera 15 (1), 121-139.

Neff, G., Wissinger, E., Zukin, S., 2005. Entrepreneurial labor among cultural producers: "Cool" jobs in "hot" industries. Soc. Semiot. 15 (3), 308-334.

Nonaka, I., 1994. A dynamic theory of organizational knowledge creation. Organ. Sci. 5 (1), 14-37. https://doi.org/10.1287/orsc.5.1.14.

Nooteboom, B., 2000. Learning by interaction: absorptive capacity, cognitive distance and governance. J. Manage. Governance 4 (1), 69-92. https://doi.org/10.1023/ A:1009941416749.

Oakley, K., 2014. Good work? Rethinking cultural entrepreneurship. In: Handbook of Management and Creativity. Edward Elgar, Cheltenham, UK, pp. 145-159.

O'Connor, J., 2004. A special kind of city knowledge": innovative clusters, tacit knowledge and the "creative city. Med. Int. Australia Incorporat. Cult. Policy 112, 131-149.

Oldenburg, R., 1989. The Great Good Place: Cafés, Coffee Shops, Community Centers, Beauty Parlors, General Stores, Bars, Hangouts and How They Get You Through the Day. Paragon House, New York.

Olma, S., 2016. In Defence of Serendipity: For a Radical Politics of Innovation. Repeater Books, London, UK.

Parrino, L., 2015. Coworking: assessing the role of proximity in knowledge exchange. Knowledge Manage. Res. Pract. 13 (3), 261-271. https://doi.org/10.1057/kmrp. 2013.47.

Polanyi, M., 1967. The Tacit Dimension. Doubleday, Garden City, New York.

Porter, M.E., 1998. Clusters and the new economics of competition. Harvard Bus. Rev. 76 (6), 77

Porter, M.E., 2000. Location, competition, and economic development: local clusters in a global economy. Econ. Dev. Quart. 14 (1), 15-34. https://doi.org/10.1177/ 089124240001400105 .

Pratt, A.C., 1997. The cultural industries production system: a case study of employment change in Britain, 1984-91. Environ. Plann. A 29 (11), 1953-1974.

Pratt, A.C., 2000. New media, the new economy and new spaces. Geoforum 31 (4), 425-436. https://doi.org/10.1016/S0016-7185(00)00011-7.

Pratt, A.C., 2014. Putting knowledge in (its) place: Knowledge transfer/exchange and clustering. Retrieved from Creative Works London website: < http://www. creativeworkslondon.org.uk/wp-content/uploads/2013/11/PWK-Working-Paper-5. pdf $>$.

Pratt, A.C., Gornostaeva, G., 2009. The governance of Innovation in the film and television industry: a case study of London, UK. In: Pratt, A.C., Jeffcutt, P. (Eds.) Creativity, Innovation and the Cultural Economy. Routledge, London \& New York, pp. 119-136.

Pratt, A.C., Jeffcutt, P., 2009. Creativity, Innovation and the Cultural Economy. Routledge, London [etc.].

Rae, D., 2004. Entrepreneurial learning: a practical model from the creative industries. Education + Training 46 (8/9), 492-500. https://doi.org/10.1108/
00400910410569614.

Raffo, C., O'Connor, J., Lovatt, A., Banks, M., 2000. Attitudes to formal business training and learning amongst entrepreneurs in the cultural industries: situated business learning through "doing with others". J. Ed. Work 13 (2), 215-230. https://doi.org/ $10.1080 / 713676987$

Reveley, J., Down, S., 2009. Stigmatization and self-presentation in Australian entrepreneurial identity formation. In: Hjorth, D., Steyaert, C. (Eds.), The Politics and Aesthetics of Entrepreneurship. Edward Elgar, Cheltenham.

Richardson, L., 2016. Sharing knowledge: Performing co-production in collaborative artistic work. Environ. Plann. A: Econ. Space 48 (11), 2256-2271. https://doi.org/10. 1177/0308518X16653963.

Richardson, L., 2017. Sharing as a postwork style: digital work and the co-working office Cambridge J. Regions, Econ. Soc. 10 (2), 297-310. https://doi.org/10.1093/cjres/ rsx002.

Richardson, L., 2018. Feminist geographies of digital work. Prog. Hum. Geogr. 42 (2), 244-263. https://doi.org/10.1177/0309132516677177.

Ross, A., 2003. No-collar: The Humane Workplace and its Hidden Costs. Basic Books, New York, N.Y.

Ryan, G.W., Bernard, H.R., 2003. Techniques to identify themes. Field Methods 15 (1), 85-109. https://doi.org/10.1177/1525822X02239569.

Saldaña, J., 2012. The Coding Manual for Qualitative Researchers. SAGE Publications Ltd, Los Angeles.

Saxenian, A., 1994. Regional Advantage: Culture and Competition in Silicon Valley and Route 128. Harvard University Press, Cambridge, MA.

Sassen, S., 1994. Cities in a World Economy. Pine Forge Press, Thousand Oaks [etc.].

Schoenberger, E., 1997. The Cultural Crisis of the Firm. Blackwell, Cambridge, MA.

Schoenberger, E., Walker, R.A., 2017. Beyond exchange and agglomeration: resource flows and city environments as wellsprings of urban growth. J. Econ. Geogr. 17 (5), 935-958. https://doi.org/10.1093/jeg/lbw012.

Schumpeter, J.A., 1934. The Theory of Economic Development: An Inquiry into Profits, Capital, Credit, Interest, and the Business Cycle. Harvard University Press, Cambridge, MA.

Scott, A.J., 1999. The cultural economy: geography and the creative field. Media Cult Soc. 21 (6), 807-817. https://doi.org/10.1177/016344399021006006.

Scott, A.J., 2000. The Cultural Economy of Cities: Essays on the Geography of ImageProducing Industries. Sage, London [etc.].

Shefer, D., Frenkel, A., 1998. Local milieu and innovations: some empirical results. Ann. Reg. Sci. 32 (1), 185-200. https://doi.org/10.1007/s001680050069.

Spinuzzi, C., 2012. Working alone together: coworking as emergent collaborative activity. J. Bus. Tech. Commun. 26 (4), 399-441. https://doi.org/10.1177/ 1050651912444070.

Spinuzzi, C., Bodrožić, Z., Scaratti, G., Ivaldi, S., 2019. "Coworking Is about community” but what Is "community" in coworking? J. Bus. Tech. Commun. 33 (2), 112-140. https://doi.org/10.1177/1050651918816357.

Storper, M.C., Venables, A.J., 2004. Buzz: face-to-face contact and the urban economy. J. Econ. Geogr. 4 (4), 351-370. https://doi.org/10.1093/jnlecg/lbh027.

Strauss, A.L., Corbin, J.M., 1990. Basics of Qualitative Research: Grounded Theory Procedures and Techniques. Sage Publications, Newbury Park [etc.].

Tierney, P., Farmer, S.M., Graen, G.B., 1999. An examination of leadership and employee creativity: the relevance of traits and relationships. Pers. Psychol. 52 (3), 591-620. https://doi.org/10.1111/j.1744-6570.1999.tb00173.x.

Tönnies, F., 1963. Community \& Society [Gemeinschaft und Gesellschaft]. Harper \& Row, New York.

Turok, I., 2003. Cities, clusters and creative industries: the case of film and television in Scotland. Europ. Plann. Stud. 11 (5), 549-565. https://doi.org/10.1080/ 0965431032000088515.

Urry, J., 2002. Mobility and proximity. Sociology 36 (2), 255-274. https://doi.org/10 $1177 / 0038038502036002002$.

Vidaillet, B., Bousalham, Y., 2018. Coworking spaces as places where economic diversity can be articulated: towards a theory of syntopia. Organization 1-28. https://doi.org/ $10.1177 / 1350508418794003$.

Weijs-Perrée, M., van de Koevering, J., Appel-Meulenbroek, R., Arentze, T., 2019. Analysing user preferences for co-working space characteristics. Build. Res. Inform. 47 (5), 534-548. https://doi.org/10.1080/09613218.2018.1463750.

Wenger, E., 1999. Communities of Practice: Learning, Meaning, and Identity. Cambridge University Press, Cambridge.

Wijngaarden, Y., Hitters, E., Bhansing, P.V., 2019a. Close to the 'local cool': creative place reputation in Dutch 'ordinary cities'. Creative Ind. J. 12 (1), 86-104. https://doi.org/ $10.1080 / 17510694.2018 .1551712$.

Wijngaarden, Y., Hitters, E., Bhansing, P.V., 2019b. 'Innovation is a dirty word': contesting innovation in the creative industries. Int. J. Cult. Policy 25 (3), 392-405. https://doi.org/10.1080/10286632.2016.1268134.

Winkel, C.V., Gielen, P.J.D., Zwaan, K., 2012. De hybride kunstenaar. De organisatie van de artistieke praktijk in het postindustriële tijdperk. AKV/St. Joost., Breda \& Den Bosch. 